RESEARCH SUPPORT

MARCH 1995

SCHOOL OF BUSINESS ADMINISTRATION

ON THE SEQUENCING OF PRIVATIZATION IN TRANSITION ECONOMIES

WORKING PAPER \#9550-11 REVISION 1

GAUTAM AHUJA

DOCTORAL CANDIDATE

CORPORATE STRATEGY

UNIVERSITY OF MICHIGAN

SUMIT K. MAJUMDAR

CORPORATE STRATEGY

UNIVERSITY OF MICHIGAN 

ON THE SEQUENCING OF PRIVATIZATION

\title{
IN TRANSITION ECONOMIES
}

\author{
by \\ Gautam Ahuja \\ School of Business Administration \\ University of Michigan \\ Ann Arbor, MI 48109 \\ Phone: (313) 763-8866 \\ Fax: (313) 763-5688 \\ and \\ Sumit K. Majumdar \\ School of Business Administration \\ University of Michigan \\ Ann Arbor, MI 48109 \\ Phone: (313) 763-4610 \\ Fax: (313) 936-6631
}

March, 1995 


\title{
ON THE SEQUENCING OF PRIVATIZATION IN TRANSITION ECONOMIES
}

\begin{abstract}
We present an empirical criterion for establishing privatization priorities for state-owned enterprises. Our approach differs from past research and prescription on privatization in that our criterion uses firm performance, rather than market structure, as the basis for deciding the sequence in which a group of firms are privatized. We argue that sequencing is relevant in that the order in which a group of state enterprises are taken up for privatization has efficiency implications, and an appropriate sequence based on efficiency considerations can lead to welfare gains. We build a series of models which indicate that, ceteris paribus, privatizing inefficient enterprises before efficient ones is a superior sequence as compared to one which reverses this order. These models also demonstrate that the size of the firms to be privatized is an important contingency moderating our result. Specifically, optimal privatization sequencing should account for both performance levels and size of the enterprises. Our models enable us to construct an improvement index for individual firms.' This improvement index, which accounts for both size and relative performance levels, makes possible a comparison of multiple firms, thus, facilitating the construction of a priority schedule. We use this index approach to construct such a schedule for a sample of Indian service sector firms, and demonstrate that our approach aids policy-makers in transition economies as they undertake to privatize state-owned enterprises.

JEL Classification: L22 - Public Enterprises; L23: - Privatization; O53 - Asia including Middle East; P21 - Planning, Coordination and Reform
\end{abstract}




\section{Introduction}

The experience of economies trying to privatize large numbers of state-owned enterprises indicates that the privatization process is likely to be slow, and drawn out, rather than swift and all encompassing (Laban and Wolf, 1993; Roland, 1994). Big-bang, or mass privatization, does not appear to be feasible for most transition economies, and the issue of sequencing in privatization acquires policy importance, raising two questions; first, is sequencing required, and, second, if so, what principles should underlie this sequencing? In this paper we address these questions. We argue that sequencing is relevant in that the order in which a group of state enterprises are taken up for privatization has efficiency implications, and an appropriate sequence based on efficiency considerations can lead to welfare gains. We develop a criterion with which to target state enterprises for privatization, one which will be relevant for policymakers in constructing a privatization sequence, and use data for a group of Indian state enterprises to illustrate how the criterion that we develop may be actually applied in practice.

This paper unfolds as follows. Section 2 is the principal section of the paper in which we develop our conceptual arguments. It consists of four sub-sections. In the first of these we discuss the basic rationale for privatization. We address the issue of what is it that policymakers seek as they attempt to privatize state-owned enterprises, and also suggest that there is likely to be significant heterogeneity in performance' within state-owned enterprises' which researchers and policy-makers ignore. In the second sub-section we discuss the motivations associated with big-bang privatization and the empirical consequences of such a privatization approach, as have emergerd so far. Following on, we demonstrate that, in the presence of performance heterogeneity, the temporal sequence in which firms are taken up for privatization has welfare implications. - We analytically show that the privatization of inefficient enterprises earlier, and relatively efficient enterprises later, leads to inter-temporal efficiency gains. In the sub-section that follows we discuss how our approach compares with other approaches with respect to the sequencing of privatization. In Section 3 we demonstrate the significant heterogeneity in performance which exists between state enterprises in India, and develop an 
illustrative priority schedule for the privatization of state enterprises in the Indian services sector based on our approach. Section 4 concludes the paper.

\section{Privatization: Rationale and the Need for Sequencing}

(a) Rationale: The Motivation for Privatization

Privatization is principally a means of improving the technical efficiency of an enterprise (Caves, 1990). The technical or productive efficiency of an enterprise refers to it's ability to be productive in transforming inputs into maximum outputs. While privatization may, under certain conditions, lead to higher growth and improved allocative efficiency there are no broadbased a-priori rationales linking privatization to such outcomes. Privatization remains, essentially, a strategy for the improvement of productivity, with the improvement in enterprise productivity due to privatization resulting from one or more of the following factors.

First, privatization leads to a change in the objective function of the firm, with a multiplicity of social objectives and political agendas, operationalized via re-distribution to favored interest groups, high wage and employment levels and patronage, being replaced by a simpler and less ambiguous, objective: that of profit-maximization; second, privatization leads to a hardening of the budget constraint by ensuring that neither funds nor survival are assured in the new environment; for example, subsidies to loss-making enterprises are curtailed, and incentives are created to enhance enterprise efficiency. Third, privatization leads to superior monitoring by interested owners, and brings the pressures of the capital market to bear upon the managers of the privatized enterprise, since the transferability of private ownership rights reveals information via stock prices; and, fourth, privatization reduces state interference and political adhocism in the conduct of enterprise business activities. With public ownership there is scope for operational intervention .. since governments may use public enterprises for political and distributional ends and provide loss-subsidies to enterprises which fundamentally distort their day-to-day on-going pricing decisions. Privatization helps eliminate such operational distortions, and enables the enterprises to focus on their core operational activities. 
The above theoretical ideas, in essence, encapsulate the economic benefits associated with privatization. While the ideas are important, in their current form they are inadequate for policy-making purposes on at least two counts. First, theory is silent on the issue of sequencing. Theory is articulated in an a-temporal context, and postulates of existing theory cannot really be utilized to address questions with a temporal dimension. Second, theory does not enable an exploration of the fact that the benefits associated with privatization may accrue unequally to different firms. Some enterprises may already be efficient, while others are relatively inefficient. Many other factors, such as management differences; or sector-specific considerations, can lead to significant performance variations even between state-owned firms (Aharoni, 1993). The privatization logic stated above may, then, be more applicable to certain firms than to others. For instance, some firms may enjoy better managerial supervision and relative freedom from state intervention. Such firms may already be performing efficiently, and may stand to benefit relatively little from privatization. On the other hand, there may be firms which are performing extremely poorly, and would, therefore, benefit significantly from privatization. This variation in the performance of state-owned firms is a contingency that existing theory does not investigate.

We take the above gaps in existing theory as the starting point of our analysis. We present a model which incorporates two elements as its central features; first, privatization will be completed over a period of time, rather than instantaneously; and, second, there exist variations in efficiency even between state-owned enterprises. We investigate the implications of privatization in an economy marked by these two features and suggest that the order in which enterprises are sequenced for privatization has welfare implications.

(b) Sequencing:-The Rise and Fall of Big-Bang-Privatization

Why does sequencing matter? Hitherto, the big-bang approach to privatization has envisaged fast-paced privatization through the mass selling-off of state enterprises, leading to a completion of the process in a very short span of time. Among the objectives driving a highspeed approach has been the necessity of achieving a critical mass of private ownership, the need 
for getting the State out of micro-management of the economy, and preventing the large scale de-capitalization of state enterprises. These were some of the reasons cited for pushing urgency in the privatization process (Roland, 1994). First, private property provides the incentives necessary for superior performance; otherwise, there is a danger of inertia for firms because of the existence of public hand-outs and the lack of a need to respond to market signals. Second, if the state has an interventionist orientation, it cannot but help interfere in the economic activities of the population, with an especially strong predilection to do in state-owned enterprise over which it has control. Third, in the absence of clarified property rights, achieved through highspeed ownership transfer, there is the possibility of expropriation of enterprise control by already entrenched managers who have de-facto enterprise control but not the legitimately-assigned property rights associated with ownership.

Although the big-bang approach found significant conceptual and policy support at the beginning of the transition period, and, consequently, high-speed privatization was tried out in erstwhile Czechoslovakia, Poland, Russia, its desirability has been increasingly questioned (Lipton and Sachs, 1990). Further, the feasibility of high-speed privatization is being challenged, given the gap between the observed rate of privatization and the size of the stateowned sector that still exists in most-transitional economies (Laban and Wolf 1993). Political constraints, lack of institutional and administrative infrastructure, inadequate depth in capital markets, and agency problems are some of the many important reasons that make rapid privatization unlikely (Dewatripont and Roland, 1992; Portes, 1994; Vickers and Yarrow, 1991).

Rapid privatization is not just operationally unlikely, but also likely to be administratively and socially undesirable. Privatization at too rapid a pace may outstrip a country's capabilities to provide managerial resources to oversee the transition, or lead to administrative resources being seconded from other areas of State's activities which are crucial to economic development (Paul, 1985). The macro-economic impact of large-scale adjustments may be formidable, and possibly politically untenable, under schemes of instantaneous reorganization, especially in developing countries where a large proportion of the population 
exists below the poverty line (Sattar, 1989). In the absence of well-developed capital-market mechanisms, accounting rules and systems, and institutional or legal safeguards, the emergence of a large number of newly privatized enterprises may lead to a further reduction in the efficacy of allocative mechanisms," because the inherited political influence continues to be the primary means of obtaining and utilizing resources (Joskow, Schmalensee and Tsukanova, 1994). Finally, the need to create durable incentive structures, preserve domestic ownership of industrial assets in the face of limited domestic liquidity, and ensure that appropriate market values are obtained for privatized corporations on their sale, underscores the desirability of gradual privatization (Vickers and Yarrow, 1991).

The experience of economies which have attempted big-bang privatization provides instances of pitfalls. In Russia, hopes that mass privatization would be followed by mass reform and restructuring have not been realized. Former managers retain control of enterprises and have blocked sale of shares, limiting liquidity, while the state apparatus lacks the resources to implement corrective action on a wide scale. With capital market discipline and State oversight both absent, the incentives for efficiency have been muted in these enterprises (Joskow, Schmalensee and Tsukanova, 1994). Hence, the objective of increasing efficiency through privatization has been defeated.

In former Czechoslovakia, fast-paced privatization has created an extra-ordinary system of governance: privatized firms are owned by investment companies which are managed by large banks, which in turn are owned by the state, and to which the former state enterprises are heavily indebted. The banks have been reticent to call in the loans, even if they look bad, and the state authorities follow a conscious policy of not allowing bankruptcies to occur, thus perpetuating the soft-budget situation -for-firms, with-non-positive consequences on expected efficiency (Portes, 1994).

In Chile, the second phase of the privatization program, undertaken between 1975 and 1983, attempted a similar fast-paced transformation of the industrial sector, with unfortunate consequences. In an attempt to maximize revenue for the state, many enterprises were rapidly 
privatized, often without adequate financial and managerial resources. This resulted in the creation of a large number of poorly-managed, highly-leveraged enterprises unequipped to withstand the turbulence of an economy in transition. The subsequent failure of many of these enterprises resulted in their being returned to state control (Vickers and Yarrow, 1991).

The British privatization, in general recognized as a relatively orderly and successful program, provides a useful counterpoint to these experiences. In an economy with functioning market mechanisms and infrastructure, and no macro-economic adjustments or property rights problems to deal with, nevertheless, it took over fifteen years for the State to divest itself from the bulk of its enterprises (Vickers and Yarrow, 1988). Yet, state enterprises in Britain accounted for only 10.6 percent of the GDP when the privatization began in 1980 (Caves, 1990), a proportion significantly smaller than the share of state enterprises' output in the GDP of most transition economies. The challenge for transition economies, therefore, is a major one.:

The experiences cited indicate that instantaneous privatization is unlikely and unfeasible. Given this failure of instantaneous privatization, it follows that privatization will be a gradual process. Hence, theoretical and empirical investigations of privatization must account for its temporal characteristics, and a prominent problem is one of sequencing. In the context of a bigbang, or all-at-once policy of privatization, sequence is not an issue as all enterprises are simultaneously privatized. However, in the context of a policy of gradual privatization some form of sequencing of privatization activity is required. Accordingly, there is a need to investigate alternate privatization sequences and study their welfare implications. Yet, in the debates on privatization this issue has been neglected.

\section{(c) A Model of Privatization Sequencing}

Given the need for gradualism, analytically, can a model of privatization sequencing be developed? We argue that, faced with a pool of state enterprises to be privatized there are efficiency and welfare implications of choosing different sequences of privatization that policy makers have to take into account. These implications arise from two conditions which are likely to hold in most transition economies; first, there are significant variations in performance even 
amongst state-owned enterprises; and, second, privatization occurs over a period of time. To illustrate these we consider the case of an economy with two state-owned enterprises, operating at two different levels of efficiency: one designated the high efficiency level $\left(G_{H}\right)$, and one designated the low efficiency level $\left(G_{L}\right)$. By definition, $G_{H}>G_{L}$. We assume that in any given period only one of these enterprises can be privatized. Further, we assume that efficiency gains through privatization remain possible in both enterprises.

We define efficiency in terms of the ability of firms to transform a given set of inputs into a set of outputs, relative to an efficiency frontier. A firm's efficiency is captured through an efficiency score constructed by calculating the firm's output to input ratio relative to the output to input ratio of the most efficient firm in the sample. So computed, the efficiency score is bounded in the interval $[0,1]$. Firms that are unable to generate any output from their inputs are assigned a score of 0 (unlikely in practice), while the most efficient firms in the sample, will have an efficiency score of 1 . Our assumption that efficiency gains remain possible through privatization for both enterprises then implies that $G_{H}<1$ and $G_{L}<1$.

Two issues arise; does the order in which the enterprises are privatized have welfare implications; and, if so, what order is normatively desirable? We consider three cases: case (a), when the post-privatization efficiency levels $(P)$ and size are the same for both kinds of enterprise; case (b), when the post-privatization efficiency-levels differs for the two kinds of enterprises, but size remains the same; and case (c), when the post-privatization efficiency levels as well as sizes differ for the two kinds of enterprises. In the last two cases we designate $P_{L}$ as the efficiency level attained by the formerly inefficient enterprise, while $P_{H}$ is the postprivatization efficiency level of the formerly efficient enterprise. We assume that privatization leads to an improvement in efficiency;-therefore, post-privatization efficiency levels are higher than pre-privatization efficiency levels. In case (a) this implies that $\mathrm{P}>G_{H}>G_{L}$. In the two subsequent cases, (b) and (c), we treat the post-privatization efficiency levels as stochastic and assume that the distributions of $\mathrm{P}_{\mathrm{H}}$ and $\mathrm{P}_{\mathrm{L}}$ are centered at a mean higher than the observed preprivatization efficiency levels $G_{H}$ and $G_{L}$, respectively. However, in these cases we also allow 
a positive probability for the event that post-privatization efficiency levels are lower than preprivatization efficiency levels.

Under the above conditions the relationship between the efficiency score of a firm and its output is as follows. The total output of a firm is the product of its efficiency score, its input volume, and a scaling constant $\gamma$ which reflects the ratio of outputs to inputs in the most efficient firm. As stated above, for the first two parts of the analysis, we assume all firms are identical in size. Without loss of generality we normalize the input volumes of these equal sized firms to one unit for the first two cases. The total output for a firm in these cases is given by the product of its efficiency score and the scaling constant $\gamma$. For our subsequent analysis we ignore this constant $\gamma$ as it applies to all firms identically, and is thus of no relevance in sequencing comparisons between firms. With these simplifications the efficiency score of each firm is identically equivalent to its output in the case of equal sized firms.

In case three where we look at unequal sized firms, the input volume of firms is allowed to vary. The output of a firm in this case is the product of its efficiency score and its input volume, (ignoring the scaling constant $\gamma$, as before). In comparing different sequences of privatization we use total output for the economy as our measure of welfare. Since in each case the compared sequences involve usage of the same amount of inputs, the sequence that yields greater output is more desirable, ceteris paribus.

We analytically illustrate the three cases we have earlier referred to, using a three-period scenario over which transition takes place for each case. In Period 1, neither firm is privatized; in Period 2, one of the firms.is privatized but not the other; and, in Period 3, the remaining firm is also privatized.

\section{CASE 1: Same.Post Privatization.Level of.Efficiency - P}

Sequence 1: The efficient firm is privatized in the first period, and the inefficient firm is privatized in the second period.

Sequence 2: The inefficient firm is privatized in the first period, and the efficient firm is privatized in the second period. 
Efficiency Level Efficiency Level Efficiency Level Efficiency Level

Period of Efficient of Inefficient of Efficient of Inefficient Enterprise Enterprise Enterprise Enterprise

\begin{tabular}{|c|c|c|c|c|}
\hline PERIOD 0 & $G_{H}$ & $G_{L}$ & $G_{H}$ & $G_{L}$ \\
\hline PERIOD 1 & $P$ & $G_{L}$ & $G_{H}$ & $P$ \\
\hline PERIOD 2 & $P$ & $P$ & $P$ & $P$ \\
\hline
\end{tabular}

The welfare implications (W) are as follows:

Welfare implications of No Privatization (W0):

WO: Three period output if neither unit is privatized: $3\left(G_{H}+G_{L}\right)$

Welfare Implications of Sequence 1 (WI):

W1: Three period output if privatization is through Sequence 1: $G_{H}+2 G_{L}+3 P$.

Therefore, $\Delta W 1$ : Increase in output through Sequence 1: WI -W0 $=3 P-2 G_{H}-G_{L}$

Welfare Implications of Sequence 2 (W2):

W2: Three period output if privatization is through Sequence $2: G_{L}+2 G_{H}+3 P$

Therefore, $\Delta W 2$ : Increase in output through Sequence 2: $W 2-W 0=3 P-2 G_{L^{-}} G_{H}$

As $G_{H}>G_{L,} \Delta W 1<\Delta W 2$

RESULT 1: In the case of both enterprises reaching the same level of post-privatization efficiency, welfare gains are possible through an appropriate sequence of privatization. Specifically, the sequence of privatizing inefficient enterprises first, and efficient enterprises 
later, is welfare-superior to the alternate sequence of privatizing efficient enterprises first and inefficient enterprises later.

The economic intuition underlying this result is straightforward. The efficiency gains of the enterprise that is privatized earlier are available for a longer period than the efficiency gains of the enterprise that is privatized later. If the quantum of these gains differ, then the two sequences cannot have the same welfare implications. Privatizing the inefficient enterprise first ensures that the larger efficiency gains are taken earlier, and carried through a longer period. This is superior to the alternate sequence that entails taking the smaller gains first and carrying them through the longer period.

A numerical illustration makes this point clear. Assume that $\mathrm{P}=0.75, \mathrm{G}_{\mathrm{H}}=0.50$, and $\mathrm{G}_{\mathrm{L}}=0.25$. Then, the efficiency improvement in the inefficient enterprise $\left(\mathrm{P}-\mathrm{G}_{\mathrm{L}}\right)$ translates to an increase of 0.5 units, and the efficiency improvement in the efficient enterprise $\left(\mathrm{P}-\mathrm{G}_{\mathrm{H}}\right)$ translates to an output increase of 0.25 units. Then, if we follow sequence 1 , efficient enterprise privatized first, over the period of the transition we obtain an output increase of 1 unit $(0.25$ units $\times 2$ years +0.50 units $\times 1$ year). Under sequence 2 , inefficient enterprise privatized first, the increase is 1.25 ( 0.50 units $x 2$ years +0.25 units $x 1$ year). Thus, having a larger efficiency increase early makes its benefits available for more periods, and, hence, adds to cumulative output over time. The longer the transition, and the greater the difference in the marginal improvements of the two units, the greater this effect.

In the above analysis, however, we make two assumptions. First, we assume that both enterprises rise to the same level of efficiency after privatization. Second, we assume that both enterprises are of the same size. Given firm-level heterogeneity, we generalize the analysis to consider two further cases.. First, we consider the case in which the firms rise to different levels of post-privatization efficiency, but retain the assumption of identical sizes. Second, we allow both size and post-privatization efficiency levels to vary. 
CASE 2: Post Privatization Levels of Efficiency Differ for the Two Enterprises- $P_{H} \& P_{L}$ $P_{H}$ is the post-privatization efficiency level for the efficient enterprise. $P_{L}$ is the postprivatization efficiency level for the inefficient enterprise.

SEQUENCE 1: The efficient firm is privatized in the first period and the inefficient firm is privatized in the second period.

SEQUENCE 2: The inefficient firm is privatized in the first period and the efficient firm is privatized in the second period.

Description of Case

Sequence 1

Sequence 2

\begin{tabular}{lcccc}
\hline & \multicolumn{2}{c}{ Sequence 1 } & \multicolumn{2}{c}{ Sequence 2 } \\
\cline { 2 - 5 } Period & $\begin{array}{c}\text { Efficiency Level } \\
\text { of Efficient } \\
\text { Enterprise }\end{array}$ & $\begin{array}{c}\text { Efficiency Level } \\
\text { of Inefficient } \\
\text { Enterprise }\end{array}$ & $\begin{array}{c}\text { Efficiency Level } \\
\text { of Efficient } \\
\text { Enterprise }\end{array}$ & $\begin{array}{c}\text { Efficiency Level } \\
\text { of Inefficient } \\
\text { Enterprise }\end{array}$ \\
\hline PERIOD 0 & $G_{H}$ & $G_{L}$ & $G_{H}$ & $G_{L}$ \\
PERIOD 1 & $P_{H}$ & $G_{L}$ & $G_{H}$ & $P_{L}$ \\
PERIOD 2 & $P_{H}$ & $P_{L}$ & $P_{H}$ & $P_{L}$ \\
\hline
\end{tabular}

Now, the welfare implications are:

W0: Three period output if neither unit is privatized: $3\left(G_{H}+G_{L}\right)$

W1: Three period output if privatization is through Sequence 1: $G_{H}+2 G_{L}+2 P_{H}+P_{L}{ }^{(8)}$

Therefore, $\Delta W 1$ : Increase in output through Sequence 1: $2 P_{H}-2 G_{H}+P_{L}-G_{L}$ (9)

W2: Three period output if privatization is through Sequence $2: 2 G_{H}+G_{L}+P_{H}+2 P_{L} \cdot(10)$

Therefore, $\Delta W 2$ : Increase in output through Sequence 2: $2 P_{L}-2 G_{L}+P_{H}-G_{H}$ 
Again, sequencing becomes relevant given that total output gains are, in general, different under the two sequences. Specifically, it can be shown that:

$\Delta W 1>\Delta W 2$ iff $P_{H^{-}} P_{L}>G_{H^{-}} G_{L}$

$\Delta W 1<\Delta W 2$ iff $P_{H^{-}} P_{L}<G_{H^{-}} G_{L}$

$\Delta W 1=\Delta W 2$ iff $P_{H}-P_{L}=G_{H}-G_{L}$

In the case of both kinds of enterprise rising to the same post-privatization efficiency level we noted that the inefficient enterprises first sequence was unambiguously welfare-superior. In the situation where they rise to different levels of efficiency, the result is conditional. While sequence is relevant, except in the case when differences in post-privatization efficiency are identically equal to differences in pre-privatization efficiency, the welfare superiority of a particular sequence depends on the occurrence of the conditions stated above. If the event $P_{H^{-}}$ $P_{L}>G_{H}-G_{L}$ is expected to occur with certainty then clearly Sequence 1 is preferable as it leads to higher output. On the other hand, if the event $P_{H^{-}} P_{L}<G_{H}-G_{L}$ is expected to occur with certainty then Sequence 2 is preferable.

However, it is likely that ex-ante it is not known with certainty which of these events will occur. In such a situation it is the relative likelihood of occurrence of these two events which determines the optimal course of action. If the event $P_{H^{-}} P_{L}>G_{H}-G_{l}$ is more likely to occur than the event $P_{H}-P_{L}<G_{H}-\mathrm{G}_{\mathrm{L}}$, then choosing Sequence 1 is optimal. Conversely, if the event $P_{H}-P_{L}<G_{H}-G_{l}$ is more likely to occur than the event $P_{H}-P_{L}>G_{H}-G_{L}$, then choosing Sequence 2 is optimal. If both events are equally likely to occur, then the decision maker is indifferent between the two sequences.

To evaluate the relative likelihood of these various events we need information on the possible values of $P_{H}$ and $P_{L}$. We assume that the post-privatization efficiency levels can be represented by a probability distribution. We believe that after privatization moderate improvements in efficiency are most likely, and extremely large or extremely small improvements are less likely. The normal distribution appropriately reflects this composition of 
outcomes. Extremely large or small improvements in efficiency correspond to the tails of the distribution and moderate efficiency increases reflect the central part of the distribution. Accordingly, we analyze the relative likelihood of the events $P_{H}-P_{L}\left\langle G_{H}-G_{L}, P_{H}-P_{L}\right\rangle$. $G_{H}-G_{L}$, and $P_{H}-P_{L}=G_{H}-G_{L}$; under the assumption that $\mathrm{P}_{\mathrm{H}}$ and $\mathrm{P}_{\mathrm{L}}$ are normally distributed.

As analysis below indicates, under this assumption, the outcome $P_{H}-P_{L}<G_{H}-G_{L}$ occurs with a probability strictly greater than 0.5 , while the event $P_{H}-P_{L}>G_{H}-G_{L}$ occurs with a probability strictly less than 0.5 . Thus, the event $P_{H}{ }^{-} P_{L}<G_{H}-G_{L}$ is more likely to occur than the event $P_{H}-P_{L}>G_{H}-G_{L}$ and therefore, choosing Sequence 2 is preferable to choosing Sequence 1 when post-privatization efficiency levels are not known with certainty. Hence, even in the case of varying post-privatization efficiency levels, in the absence of any other information, the decision-maker is still better off in choosing Sequence 2 over Sequence 1.

We assume, as before, that $0 \leq G_{L}<G_{H}<1$ (by definition of $G_{H}$ and $G_{L}$ and the assumption that efficiency gains remain possible for all enterprises). For expositional convenience, we classify the distances $0-G_{L}$ as $\alpha$, and $0-G_{H}$ as $\beta$. Hence $\beta>\alpha$. Our interest lies in establishing the relative likelihood of $P_{H^{-}} P_{L}>G_{H^{-}} G_{L}$ vs. $P_{H^{-}} P_{L}<G_{H^{-}} G_{L}$ or, in other words, $\operatorname{Prob}\left[\left(P_{H^{-}} P_{L}\right)>(\beta-\alpha)\right]$, and $\operatorname{Prob}\left[\left(P_{H^{-}} P_{L}\right)<(\beta-\alpha)\right]$.

We assume that $P_{L}$ and $P_{H}$ are both random variables drawn independently from normal distributions centered on the difference between current efficiency level ( $G_{L}$ or $G_{H}$ respectively) and the maximum possible efficiency score which is: 1 . This specification allows postprivatization efficiency levels to fall below $G_{H}$ or $G_{L}$ respectively, or rise beyond the maximum currently observed efficiency score, with positive probabilities, while concentrating the probability mass over the likely to be observed mid-range values. Thus, while being general, this specification retains the advantage of representing the entire range of possible outcomes.

Symbolically, $P_{L} \sim N\left(\mu_{L}, \sigma_{L}^{2}\right)$ and $P_{H} \sim N\left(\mu_{H}, \sigma_{H}^{2}\right)$, where $\mu_{H}, \mu_{L}$ and $\sigma_{H}^{2}, \sigma_{L}^{2}$ are the parameters of the respective normal distributions. To obtain values for these parameters 
from the given information we use the approach suggested by Judge, et al. (1988:289). If $\mu_{L}$ is centered on the difference between $G_{L}$ and $1, \mu_{L}=(1+\alpha) / 2$. If $\mu_{H}$ is centered on the difference between $G_{H}$ and $1, \mu_{H}=(1+\beta) / 2$. We know that $1-\alpha \cong 6 \sigma_{L}$ as $6 \sigma$ covers $99.9 \%$ . of the normal distribution. Similarly; $1-\beta \cong 6 \sigma_{H}$. Hence,

$$
\begin{aligned}
& \sigma_{L} \cong(1-\alpha) / 6 \text { and, } \\
& \sigma_{H} \cong(1-b) / 6 .
\end{aligned}
$$

Therefore, $\mathrm{P}_{\mathrm{L}} \sim \mathrm{N}((1+\alpha) / 2,(1-\alpha) / 6)^{2}$ and

$$
\mathrm{P}_{\mathrm{H}} \sim \mathrm{N}((1+\beta) / 2,(1-\beta) / 6)^{2} \text {. }
$$

This parameterization provides a complete specification of the two distributions.

Given this, we know that the random variable $P_{H}-P_{L}$, being a difference of two independent normal variables, will itself be normally distributed. Further, it can easily be shown that $P_{H}-P_{L}$ will have a mean equal to the difference of the means of the two parent distributions, and a variance equal to the sum of the variances of the two distributions (Ross, 1983). Accordingly, we have

$$
\begin{aligned}
& \mathrm{P}_{\mathrm{H}}-\mathrm{P}_{\mathrm{L}} \sim \mathrm{N}\left((\beta-\alpha) / 2,\left((1-\beta)^{2}+(1-\alpha)^{2}\right) / 36\right) \\
& \text { Now, } \operatorname{Prob}\left[\left(\mathrm{P}_{\mathrm{H}}-\mathrm{P}_{\mathrm{L}}\right)>\left(\mathrm{G}_{\mathrm{H}}-\mathrm{G}_{\mathrm{L}}\right)\right]=\operatorname{Prob}\left[\left(\mathrm{P}_{\mathrm{H}}-\mathrm{P}_{\mathrm{L}}\right)>(\beta-\alpha)\right] .
\end{aligned}
$$

To obtain the probability associated with a normal random variable taking a certain set of values, we transform it to the standard normal variable $\mathrm{z}$, and use the standard normal distribution to compute the desired probability. Accordingly, we have

$$
\operatorname{Prob}\left[\left(\mathrm{P}_{\mathrm{H}}-\mathrm{P}_{\mathrm{L}}\right)>(\beta-\alpha)\right]=\operatorname{Prob}\left(\mathrm{z}>\mathrm{z}_{0}\right),
$$

where $z$ is the standard normal variable and $z$ is the transformation of the desired $P_{H}{ }^{-} P_{L}$ value to the standard normal. Thus, we obtain

$$
\begin{aligned}
& z_{0}=((\beta-\alpha)-(\beta-\alpha) / 2) /\left(\sqrt{(1-\beta)^{2}+(1-\alpha)^{2}} / 6\right) \\
& =3(\beta-\alpha) / \sqrt{(1-\beta)^{2}+(1-\alpha)^{2}},
\end{aligned}
$$


and, therefore, $\operatorname{Prob}\left(z>z_{0}\right)=\operatorname{Prob}\left(z>3(\beta-\alpha) / \sqrt{(1-\beta)^{2}+(1-\alpha)^{2}}\right)$

We know that $z_{0} \geq 0$, since $z_{0}$ is a standard normal variable and its sign is determined by its numerator, as the denominator is a standard deviation and therefore, positive. Here, the numerator is strictly positive as $\beta>\alpha$, and, given this, it can be stated that: $z_{0}>0$ for all permissible values of $\beta$ and $\alpha$. If $z_{0}>0$ then $\operatorname{Prob}\left(z>z_{0}\right)<0.50$ for all permissible values of $\beta$ and $\alpha$, as values of 0 or less occur with a probability of 0.50 in the standard normal distribution. Therefore, $\operatorname{Prob}\left[\left(\mathrm{P}_{\mathrm{H}}-\mathrm{P}_{\mathrm{L}}\right)>\left(\mathrm{G}_{\mathrm{H}}-\mathrm{G}_{\mathrm{L}}\right)\right]<0.50$, and, further, as, $P_{H}-P_{L}$ is a continuous random variable the probability of it taking any individual välue is 0 . Therefore, $\operatorname{Prob}\left[\left(P_{H}{ }^{-}\right.\right.$ $\left.\left.P_{L}\right)=\left(G_{H^{-}} G_{L}\right)\right]=0$. Hence, $\operatorname{Prob}\left[\left(P_{H^{-}} P_{L}\right)<\left(G_{H^{-}} G_{L}\right)\right]>0.50$.

RESULT 2: Even with differing post-privatization efficiency levels, welfare gains are possible through an appropriate sequence of privatization. Specifically, the sequence of privatizing inefficient enterprises first, and efficient enterprises later, will lead to welfare gains with a probability strictly greater than 0.5 . Further, to the extent that $z_{0}$ takes on values greater than 0 , which will be always, the probability of welfare gains through Sequence 2 increases.

Examining the economic intuition underlying this result is instructive. Even though postprivatization efficiency levels are permitted to vary freely in this case, the inefficient enterprises first sequence remains superior. This occurs because firms that are inefficient have greater scope to post large increases in efficiency than do firms that are already close to the efficiency frontier. The welfare effects of sequencing depend upon the relative magnitude of improvements in the two enterprises. Large improvements in efficiency are more unlikely for firms that are already very efficient. Hence, ceteris paribus, it still makes sense to privatize inefficient enterprises first.

The assumption of equal-sized enterprises is unlikely in reality, and in the erstwhile socialist and command economies the state has involved itself in a myriad of activities involving firms of widely-differing sizes. Accordingly, we need to investigate whether Result 2 holds when firm sizes differ. Consequently, we consider the case when both post-privatization efficiency levels and the size of the enterprises differ. 


\section{CASE 3: When Firm Size Differs}

Let $\delta_{\mathrm{L}}=$ size of inefficient enterprise

$\delta_{\mathrm{H}}=$ size of efficient enterprise

Three period output if neither firm is privatized:

$W_{0}=3 \delta_{H} G_{H}+3 \delta_{L} G_{L}$

W1: Three period output if privatization is through Sequence 1

$: \delta_{\mathrm{H}} \mathrm{G}_{\mathrm{H}}+2 \delta_{\mathrm{H}} \mathrm{P}_{\mathrm{H}}+2 \delta_{\mathrm{L}} \mathrm{G}_{\mathrm{L}}+\delta_{\mathrm{L}} \mathrm{P}_{\mathrm{L}}$

Therefore, $\Delta \mathrm{W} 1$ : Increase in output through Sequence 1:

$$
{ }^{2} \delta_{\mathrm{H}}\left(\mathrm{P}_{\mathrm{H}}-\mathrm{G}_{\mathrm{H}}\right)+\delta_{\mathrm{L}}\left(\mathrm{P}_{\mathrm{L}}-\mathrm{G}_{\mathrm{L}}\right)
$$

W2: Three period output if privatization is through Sequence 2:

$$
2 \delta_{\mathrm{H}} \mathrm{G}_{\mathrm{H}}+\delta_{\mathrm{H}} \mathrm{P}_{\mathrm{H}}+\delta_{\mathrm{L}} \mathrm{G}_{\mathrm{L}}+2 \delta_{\mathrm{L}} \mathrm{P}_{\mathrm{L}}
$$

Therefore, $\Delta \mathrm{W} 2$ : Increase in output through Sequence 2:

$$
\delta_{\mathrm{H}}\left(\mathrm{P}_{\mathrm{H}}-\mathrm{G}_{\mathrm{H}}\right)+2 \delta_{\mathrm{L}}\left(\mathrm{P}_{\mathrm{L}}-\mathrm{G}_{\mathrm{L}}\right)
$$

Let $k=\frac{\delta_{H}}{\delta_{L}} \quad$ (ratio of sizes of the two firms)

Then it can be shown that:

$$
\begin{array}{lll}
\Delta W 1>\Delta W 2 & \text { iff } & k P_{H}-P_{L}>k G_{H}-G_{L} \\
\Delta W 1<\Delta W 2 & \text { iff } & k P_{H}-P_{L}<k G_{H}-G_{L} \\
\Delta W 1=\Delta W 2 \text { iff } & k P_{H}-P_{L}=k G_{H}-G_{L}
\end{array}
$$

Our interest, as before, lies in establishing the relative likelihood of these three conditions.

We assume, as in Case 2, $P_{H} \sim N\left(\frac{(1+\beta)}{2},\left(\frac{1-\beta}{6}\right)^{2}\right)$ and $P_{L} \sim N\left(\frac{(1+\alpha)}{2},\left(\frac{1-\alpha}{6}\right)^{2}\right)$

then

$k P_{H}-P_{L} \sim N\left(\frac{k(1+\beta)-1-\alpha}{2}, k^{2}\left(\frac{1-\beta}{6}\right)^{2}+\left(\frac{1-\alpha}{6}\right)^{2}\right)$ as, $\mathrm{kP}_{\mathrm{H}}-\mathrm{P}_{\mathrm{L}}$ is a linear combination of

two normally distributed, independent random variables.

Now, Prob $\left[\left(k P_{H}-P_{L}\right)>\left(k G_{H}-G_{L}\right)\right]=\operatorname{Prob}\left[\left(k P_{H}-P_{L}\right)>(k \beta-\alpha)\right]$. 
To obtain the probability associated with a normal random variable taking a certain set of values, we transform it to the standard normal variable $\mathrm{z}$, and use the standard normal distribution to compute the desired probability. Accordingly, we have $\operatorname{Prob}\left[\left(k P_{H}-P_{L}\right)>(k \beta-\alpha)\right]=$ $\operatorname{Prob}\left[z>z_{0}\right]$ where $\mathrm{z}$ is the standard normal variate and $z_{0}$ is the transformation of the given

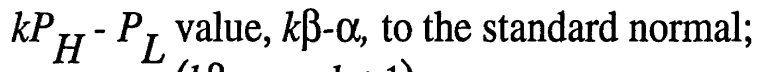

$$
z_{0}=\frac{(k \beta-\alpha-k+1)}{2 \sqrt{k^{2}\left(\frac{1-\beta}{6}\right)^{2}+\left(\frac{1-\alpha}{6}\right)^{2}}}
$$

The sign of this expression is determined by the numerator as the denominator is a standard deviation. Positive values of $z_{0}$ imply that the Prob $\left(z>z_{0}\right)$ must be less than 0.5 , and hence the $\operatorname{Prob}\left(\mathrm{z}<\mathrm{z}_{0}\right)$ is greater than 0.50 .

It can be seen that the numerator of $z_{0}$ will be positive iff

$$
k<\frac{1-\alpha}{1-\beta} \text { i.e. } \frac{\delta_{H}}{\delta_{L}}<\frac{1-\alpha}{1-\beta}
$$

Result 3: If firms differ in size and post-privatization efficiency levels Result 2 holds, provided the relative sizes of the enterprises satisfy the equation above.

In the case of equal-sized firms we had noted that Sequence 2 was associated with a higher probability of welfare gains relative to Sequence 1. Here we note that this result holds only for values of $\mathrm{k}$ which satisfy the above condition. The intuition for this result is that while Result 2 holds for equal-sized enterprises it may not hold if one of the enterprises is very large relative to the other. If the large enterprise is also a very inefficient one, Result 2 will hold, afortiori, as privatizing it early will provide potentially large efficiency gains (large increases in efficiency over a large volume); however, if the efficient enterprise is relatively large this result may be overturned as even small increases in efficiency over a large volume, may be larger than large increases over a small volume. While sequencing will have welfare implications, the appropriate order will need to be based on computations accounting for both efficiency levels and sizes of the enterprises. 
Our condition $\frac{\delta_{H}}{\delta_{L}}<\frac{1-\alpha}{1-\beta}$, can be rewritten as: $\delta_{H}(1-\beta)<\delta_{L}(1-\alpha)$. In this form its intuitive content becomes clearer. The left hand side of the inequality is a product of the size of the first enterprise and its distance from the efficiency frontier. It represents the total potential for improvement in that enterprise. We call this product the improvement index. The right hand side of the inequality represents the improvement index for the second enterprise. Our condition then implies simply that the enterprise with the higher improvement index should be chosen for earlier privatization. The improvement index, thus, provides us with a basis for establishing a sequence among any number of corporations. Computing the improvement index for a group of firms and ranking them on the basis of these scores, will provide a list of privatization priorities consistent with inter-temporal efficiency maximization.

The above analysis indicates that sequencing in privatization clearly has welfare implications. Further, it indicates that in constructing an appropriate sequence it is necessary to account for both size and performance levels of the enterprises to be privatized. Privatization of small, efficient enterprises is likely to contribute relatively little in output improvements, whereas privatization of large, inefficient enterprises will contribute large gains. Based upon the principle that taking large gains in efficiency, made in earlier time-periods, and sustained over time, leads to greater cumulative output privatization policy should focus on large, inefficient enterprises first, and leave small efficient enterprises to be targeted last. Enterprises that are intermediate in size and efficiency should be targeted after the large, inefficient enterprises, but before the small, efficient ones. The matrix in Figure 1 reflects these privatization priorities and provides guidelines for policy-making.

\section{[Insert Figure 1 Here]}

\section{(d) A Comparison with other Approaches to Privatization Sequencing}

How does our approach compare with other existing approaches? Drawing upon extant literature, we identify three other schemes of privatization sequencing, which are the structural, random, and political economy approaches. The structural approach focuses on market structure 
as an intervening variable for deciding the order of privatization (Vickers and Yarrow, 1991). Enterprises operating in competitive sectors of the economy are privatized earlier, while enterprises in sectors marked by monopoly are left for later privatization. The logic that privatization might exacerbate allocative inefficiencies in markets characterized by monopoly has formed the economic basis of this approach, but this approach suffers from three shortcomings.

First, issues of allocative efficiency are confounded with those of technical efficiency. While allocative efficiency considerations will be associated with state enterprises operating in sectors marked by natural monopoly, it is not clear that postponing their privatization is welfare enhancing. If allocative efficiency implications are adverse, then it is debatable whether enterprises should be privatized at all (Caves, 1990). Conversely, if the allocative inefficiency problems are not very significant, but technical inefficiencies abound in a group of monopolistic enterprises, delaying privatization can entail significant losses. A second problem with the structural approach lies in its inability at providing guidance in establishing priorities between enterprises which share the same structural characteristics. For instance, this approach provides no basis for establishing a sequence between competitive enterprises, or between monopolies. Thus, it provides only a partial ordering and leaves the sequencing problem incompletely resolved.

A third problem is that, like all structural criteria, it entails making inferences about conduct and performance (Scherer and Ross, 1990). By contrast, a performance-based criterion relies on direct measurement and, therefore, reduces error inherent in attribution. Further, such a criterion avoids relying upon stylized regularities which may not hold in individual cases. For instance, even if monopolies are technically inefficient;-it-does not-imply that all-monopolies are always inefficient. A structural criterion would classify all monopolies similarly, and thus fail to distinguish between efficient and inefficient monopolies. A performance criterion makes no such assumption, but examines each monopoly to determine its relative efficiency. 
The random approach implies that Government follows no clear policy. Simply put, enterprises are sold or given away on a first-come first served basis. Enterprises which find ready buyers are privatized first, and the remainder remain under state control. The net result of this strategy is easily visible: Crown jewels, well run enterprises with commercial potential, move into private hands while white elephants, relatively inefficient and troubled enterprises, remain with the state. The economic basis of such an approach, if there is one, is short-term revenue maximization, and the approach suffers from three shortcomings. First, short-term exigencies drive the choice of enterprises privatized. In the absence of clearly-set criteria governing privatization, divestiture takes on the aspect of a fire sale. Second, the continuation of the soft budget constraints for the unprivatized enterprises imply that performance in the stateowned enterprises continues to be poor. The shock of privatization is administered to enterprises that benefit least from it, while those that need the shock are left to languish. Given our results, this analysis implies that the largest inefficiencies are carried through for the longest period. A third problem is that, in addition to neglecting technical efficiency, it also ignores allocative efficiency considerations.

The political economy approach is a variant of the random approach and argues that the best firms in the state-owned sector should be privatized earliest (Roland, 1994). Such firms have the highest likelihood of being successful, and their success can be used to build constituencies for further reform. There is some strength in this argument, as political constraints operate in most transition economies. However, political support is acquired at the cost of efficiency, and this trade-off should be made explicit and recognized. Further, a serious constraint to this approach is that there are likely to be only a few firms which fall into this category of best... The problem of tackling the rest, and prioritizing between them, still remains unresolved, which the use of a performance criteria can help in resolving.

None of the other approaches to privatization sequencing capture the economic logic reflected in our technical efficiency and size criteria. To the extent that each of these approaches ignores the efficiency implications of alternate sequences of privatization a significant loss of 
resources is implied. Given the importance of the state-owned-sector in most transition economies, the cumulative effects of these inefficiencies are likely to be large. Complementing our perspective with the structural and political economy perspectives we suggest that our approach can be used to identify egregious instances of technical inefficiency among stateowned firms and target them for privatization; simultaneously, market structure characteristics of these firms, as well as the political environment, can be kept in mind in deciding the precise sequence of privatization.

\section{Empirical Illustration}

\section{(a) Context and Empirical Procedures}

In this section we use data from a sample of Indian 27 state-owned enterprises to illustrate the above analysis. We first compute efficiency scores for the enterprises using data envelopment analysis, a linear programming approach which has been used to measure technical efficiency in many contexts. We note from our results, that we discuss later on in this section, that there is marked heterogeneity in the performance of the evaluated state-owned enterprises. Both relatively efficient and highly inefficient enterprises co-exist within the same sector. Hence, the assumption that the state-owned-sector is marked by significant performance heterogeneity finds empirical support, at least in the Indian context. We then use the conditions derived in Section 2 to construct an illustrative privatization schedule for state-owned enterprise in the services sector of the Indian economy.

As developed by Charnes, Cooper and Rhodes (1978), Farrell's (1957) output-input measure of performance is generalized to a multiple output-input case by means of a fractional mathematical program, where the ratio of the weighted outputs to weighted inputs (an efficiency ratio) for each firm-level observation being evaluated is maximized. There are a total of $\mathrm{n}$ firmlevel observations being evaluated. The data used for each observation $j$ (where $j$ are the observations: $j=1,2, \ldots . . . . . n)$ are as follows: each observation consumes varying amounts of $\mathrm{m}$ inputs to produce $s$ outputs. Specifically, observation $\mathrm{j}$ consumes $\mathrm{X}_{\mathrm{j}}=\left\{\mathrm{x}_{\mathrm{ij}}\right\}$ of inputs $(\mathrm{i}=$ $1, \ldots . . m)$ and produces amounts $Y_{j}=\left\{y_{r j}\right\}$ of outputs $(r=1, \ldots . s)$. It is assumed that $x_{i j}>0$ and 
$y_{r j}>0$. The $s x n$ matrix of output measures is denoted by $Y$ and the $m x n$ matrix of input measures is denoted by $\mathrm{X}$.

For the $\mathrm{k}^{\text {th }}$ observation (among the $\mathrm{j}$ total observations) for which efficiency is being evaluated, the objective of the empirical exercise is to maximize the value of $h_{k}$ which is the ratio of outputs to inputs, and the values of $u$ and $v$; this function is expressed as:

$$
h_{k}(u, v)=\sum_{r=1}^{s} u_{r} y_{r k} / \sum_{i=1}^{m} v_{i} x_{i k}
$$

In the above expression, $h_{k}$ is a ratio measure of performance as to how efficient each observation was with regard to converting a set of inputs jointly and simultaneously into a set of outputs. For each $\mathrm{k}^{\text {th }}$ observation, $\mathrm{y}_{\mathrm{rk}}$ are the multiple outputs which result from the conversion of $x_{i k}$ inputs; $u_{r}$ and $v_{i}$ are weights which are calculated as values to be assigned to each output and input in order to maximize the efficiency rating, $\mathrm{h}_{\mathrm{k}}$, of the observation being evaluated.

Without any more constraints (37) is unbounded. Additional constraints are introduced with respect to every other firm-level observation to reflect the condition that the efficiency ratio be less than or equal to unity, or in other words, no observation can be super-efficient. The mathematical programming problem that results is:

$$
\max \mathrm{h}_{\mathrm{k}}(\mathrm{u}, \mathrm{v})=\sum_{\mathrm{r}=1}^{\mathrm{s}} \mathrm{u}_{\mathrm{r}} \mathrm{y}_{\mathrm{rk}} / \sum_{\mathrm{i}=1}^{\mathrm{m}} \mathrm{v}_{\mathrm{i}} \mathrm{x}_{\mathrm{ik}}
$$

subject to:

$$
\begin{aligned}
& \sum_{r=1}^{s} u_{r} y_{r j} / \sum_{i=1}^{m} v_{i} x_{i j} \leq 1(\text { for } j=1,2, \ldots 0, \ldots n) \\
& u_{r}>0 \quad(\text { for } r=1,2, \ldots \ldots s) \\
& \left.v_{i}>0 \text { (for } i=1,2, \ldots . . m\right)
\end{aligned}
$$


The constraint in (40), therefore, ensures that the ratio measure of performance is not greater than one for any observation in the entire observation set, while the constraints in (41) and (42) are positivity constraints and are strictly greater than zero.

In (39), $w_{k}$ is the objective function value which is the efficiency score for the $k^{\text {th }}$ observation being evaluated. Each DEA model seeks to determine which subsets of the $n$ observations determine parts of an envelopment surface. In the L.P. formulation the optimal value (optimal $=^{*}$ ) of $\mathrm{w}_{\mathrm{k}}$ is an efficiency indicator which measures the distance a particular firm-level observation lies from the frontier. The $\mathrm{k}^{\text {th }}$ firm-level observation is efficient if $\mathrm{w}^{*}=$ 1 in (39). This observation is inefficient if it does not lie on the frontier or $w_{k}{ }^{*}<1$. The optimization process in (39) is repeated $\mathrm{n}$ times, once for each firm-level observation for which efficiency is to be evaluated. In other words, the L.P. is solved with $\left(X_{k}, Y_{k}\right)=\left(X_{j}, Y_{j}\right)$ for $j=$ $1,2, \ldots \mathrm{k}, \ldots \mathrm{n}$. Each time the optimization is carried out data for other observations form part of the constraint set. The objective function values obtained partition the data-set into two parts: one consisting of efficient observations and the other consisting of observations which are inefficient and where $\mathrm{w}_{\mathrm{k}} *<1$.

Our sample consists of 27 service-sector Indian state-owned enterprises for which we have firm level data for five years: 1987 to 1991. Data are obtained from the Center for Monitoring the Indian Economy in Bombay, India. We pool the data for all five years for all firms. We use one key output: value added by operations. Value added is a standard measure of firm-level performance (Jackson \& Palmer, 1988). Capabilities are encapsulated in physical capital and human capital, and we therefore use two inputs: total fixed assets and number of employees. To compute managerial efficiencies we use the Banker, Charnes and Cooper (1984) algorithm which controls for scale efficiencies.

(b) Implications Resulting from the Empirical Analysis

As data in Tables 1 and 2 reveal, there is significant compositional and performance heterogeneity between the firms studied. Table 1 shows a great deal of variation in the composition of state enterprises. The median figures for value added, gross fixed assets and 
employment are consistently and significantly less than the mean figures, suggesting high skewness in the data. Efficiency variations can be assessed by examining data with respect to the standard deviation, the inter-quartile range and the coefficient of variation of the calculated efficiency scores for the sample firms. ' The standard deviation is 0.262 given a mean score of 0.445 , while the inter-quartile range is 0.416 . The range of scores is 0.847 . These parameters point to the extremely wide performance variations within state enterprises belonging to one sector alone.

We use the analysis developed in Section 2 to draw up an illustrative privatization schedule for the firms in our sample, and construct the improvement index for the firms in the sample. We subtract the firm's efficiency score from the maximum obtainable score of 1 , and call this the efficiency gap. We use total assets as a measure of the firm's size. The improvement index for a firm equals the product of its size and its efficiency gap. Table 3 provides details of the computations of the improvement index for all the firms and its analysis raises interesting implications. First, we note that our technique provides a complete schedule of privatization priorities. Firms with large improvement index values promise greater returns to privatization than firms with small improvement index values and are therefore better candidates for early privatization. Second, we note that improvement possibilities are heterogenously distributed in the sample of enterprises. A few large, inefficient enterprises have' very large improvement index scores, while many firms have relatively small improvement index scores. In policy terms this implies that focus of privatization activities on a few large corporations is important so as to remove the bulk of the inefficiency in the state enterprises that have been evaluated.

Interestingly, firms .numbered .1. and 2, as listed by size .in. Table 3, are . Air India and Indian Airlines. These firms operate in the international and domestic civil aviation sectors respectively, and as the data show both use large quantities of physical capital stock, as well as employ a large number of personnel, to provide the services expected of them. Both of them have the potential to make significant efficiency gains, given data on current performance that 
have been generated. If just these two airlines are subject to the shock of privatization, the efficiency gains that can result approximate over 40 percent of the total efficiency gains possible if all twenty-seven service sector enterprises listed in the table were to be privatized.

Evidence from Britain (Vickers and Yarrow, 1991) shows that significant efficiency gains have occurred for the state-owned airline, British Airways, that was privatized. Such evidence, in conjunction with the analysis that we carry out, points to a critical need for the Indian Government to concentrate its efforts on trying to privatize these firms given their critical presence in the economy in terms of the capital investment that they have sucked up, in spite of recent instances of strikes by personnel of Air-India and Indian Airlines in resistance to privatization efforts. Arguably, the political economy dimension does significantly impact on privatization efforts, but the loss of rents currently accruing to the less than a hundred thousand personnel employed in these firms in India is likely to be more than adequately replaced by the welfare gains that will accrue to the economy as a whole as a result of the increased efficiency of just these firms alone. Simultaneously with privatization, the state has to withdraw from day-today operations of the sold-off enterprise, as occurred with British Airways. As recounted in Mhatre (1992), a proposal to privatize Air India and Indian Airlines, and yet retain full operational control by the government ministry concerned, suggested by the Indian Minister of Civil Aviation, is likely to be short-sighted in the extreme.

\section{Conclusions}

In this paper we propose the use of a performance-based criterion for establishing privatization priorities. We argue that, in a scheme of gradual privatization, the fact that different enterprises are performing at different efficiency levels has important welfare implications. These welfare implications arise on account - of the temporal dimension of the privatization problem. If all enterprises cannot be privatized in the same period then, clearly, some enterprises will need to be privatized earlier than others. Enterprises which are privatized earlier will post improved performance for a longer period than enterprises which are privatized later. Given this scenario it makes sense to prioritize the privatization of those enterprises which 
are likely to post the largest improvements in performance. Such a scheme will ensure that the largest gains are taken earliest and the relatively smaller gains are taken only later in the transition period, and hence cumulative efficiency gains over the transition period are maximized:

We build a series of analytical models which formalize these intuitions. These models indicate that, ceteris paribus, privatizing inefficient enterprises before efficient ones is a superior sequence as compared to one which reverses this order. These models also demonstrate that the size of the firms to be privatized is an important contingency moderating our result. Specifically, optimal privatization sequencing should account for both performance levels and size of the enterprises. Our models also enable us to construct an improvement index for individual firms. This improvement index, which accounts for both size and relative performance levels, makes possible a comparison of multiple firms, thus, facilitating the construction of a priority schedule. We use this index approach to construct such a schedule for a sample of Indian service sector firms.

The improvement index based approach to sequencing of privatization provides many advantages. First, it provides a systematic basis for understanding the implications of sequencing in privatization, and hence provides theoretically grounded policy guidelines. This is superior to the ad hoc approach that has characterized the privatization experience so far. Privatization policy based on clear and consistent logic reduces investor uncertainty and enhances state credibility by indicating a Government in control of the process rather than one that that is characterized by political ad-hocism.

Second, our approach provides a micro, firm-level focus, and thus moves beyond the sectoral or macro approach that has dominated the transition debate (Portes, 1994). This micro focus provides multiple benefits: first, firm-level information can be incorporated directly into the policy making process; second, actions can be targeted to focus on specific firms which are major sources of inefficiency, rather than on more broadly-defined sectors. For instance, our approach can draw attention to the need for improving, say, electric utility $x$ which is under 
performing, rather than try to reform the entire utilities sector, and such an approach can be of considerable help in conserving and utilizing scarce state-resources with respect to enterprise reform.

Finally, there is the issue of signals to be sent to current state-owned enterprises with a view to enhancing their efficiency. Past research has shown that the prospect of privatization has led to gains in technical efficiency of a magnitude similar to that gained through privatization itself (Yarrow, 1986). A government policy which is committed to the enhancement of industrial efficiency can utilize our performance-based criteria in sending signals to appropriate enterprises, the larger and more inefficient firms in the state-owned sector, that their fate is in the hands of new owners, with different sets of priorities, who may radically alter the status-quo. Such signals may by themselves engender performance improvements. In this context, the statement of a former chief executive of state-owned Indian Airlines on whether the proposed introduction of private airlines competing domestically with the state-owned carrier in lucrative trunk routes would lead to operational changes and large-scale redundancies, is particularly apposite: "I suppose if one's long-term security becomes a question of doubt, then that itself may compel a certain willingness to change (Mhatre, 1992: 83)." 


\section{REFERENCES}

Aharoni, Y. 1993. In search for the unique: can firm-specific advantages be evaluated? Journal of Management Studies, 30: 31-49.

Banker, R. D. Charnes, A. and Cooper, W. W. 1984. Some Models for Estimating Technical and Scale Efficiencies in Data Envelopment Analysis. Management Science, 30. 9: 1078-1092.

Caves, R.E. 1990. Lessons from privatization in Britain. State enterprise behavior, public choice and corporate governance. Journal of Economic Behavior and Organization 13: 145-169.

Charnes, A, Cooper, W.W. and Rhodes, E. 1978. Measuring the Efficiency of Decision Making Units." European Journal of Operations Research, 2.6: 429-444.

Dewatripont, M. and Roland, G. 1992. The virtues of gradualism and legitimacy in the transition to a market economy. Economic Journal 102:291-300

Farrell, M. J. 1957. The Measurement of Productive Efficiency. Journal of the Royal Statistical Society Series A (General). 120.3: 253-281.

Jackson, P. M. and Palmer, A. J. 1988. The economics of internal organization: The efficiency of parastatals in less developed countries. In P. Cook and C. Kirkpatrick (Eds.) Privatization in less developed countries: 195-216. New York: St. Martin's Press.

Joskow, P.L., Schmalensee, R., and Tsukanova, N. 1994. Competition Policy in Russia During and After Privatization. Brooking Papers on Economic Activity: Microeconomics. 301379.

Judge, G.G., Hill, R.C., Griffiths, W.E., Lutkepohl, H., and Lee, T.C. 1988. Introduction to the theory and practice of econometrics. New York: Wiley and Sons.

Laban, R. and Wolf, H. C. 1993. Large-scale privatization in transition economies. American Economic Review, 83: 1199-1210.

Lipton, D. and Sachs, J. 1990. Privatization in Eastern Europe: the case of Poland. Brookings Papers on Economic Activity 2. 293-341.

Mhatre, K. 1992. Privatization, "Indian style". Air Transport World. November. 83-86.

Paul, S. 1985. Privatization and the public sector. Finance and Development. December 43-45.

Portes, R. 1994. Transformation traps. Economic Journal 104:1178-1189..

Roland, G. 1994. On the speed and sequencing of privatization and restructuring. Economic Journal 104:1158-1168. 
Ross, S. 1983. Stochastic Processes. Wiley.

Sattar, Z. 1989. Privatizing public enterprises in Bangladesh: A simulation analysis of macroeconomic impacts. Applied Economics 21:1159-1176.

Scherer, F. M. and Ross, D. 1990. Industrial market structure and economic performance. Chicago: Rand McNally.

Vickers, J. and Yarrow, G. 1991. Economic perspectives on privatization. Journal of Economic Perspectives. 5. 2. 111-132.

Yarrow, G. 1986. Privatization in theory and practice. Economic Policy. 2. 323-364. 
Figure 1: Privatization Priorities for Policy Makers

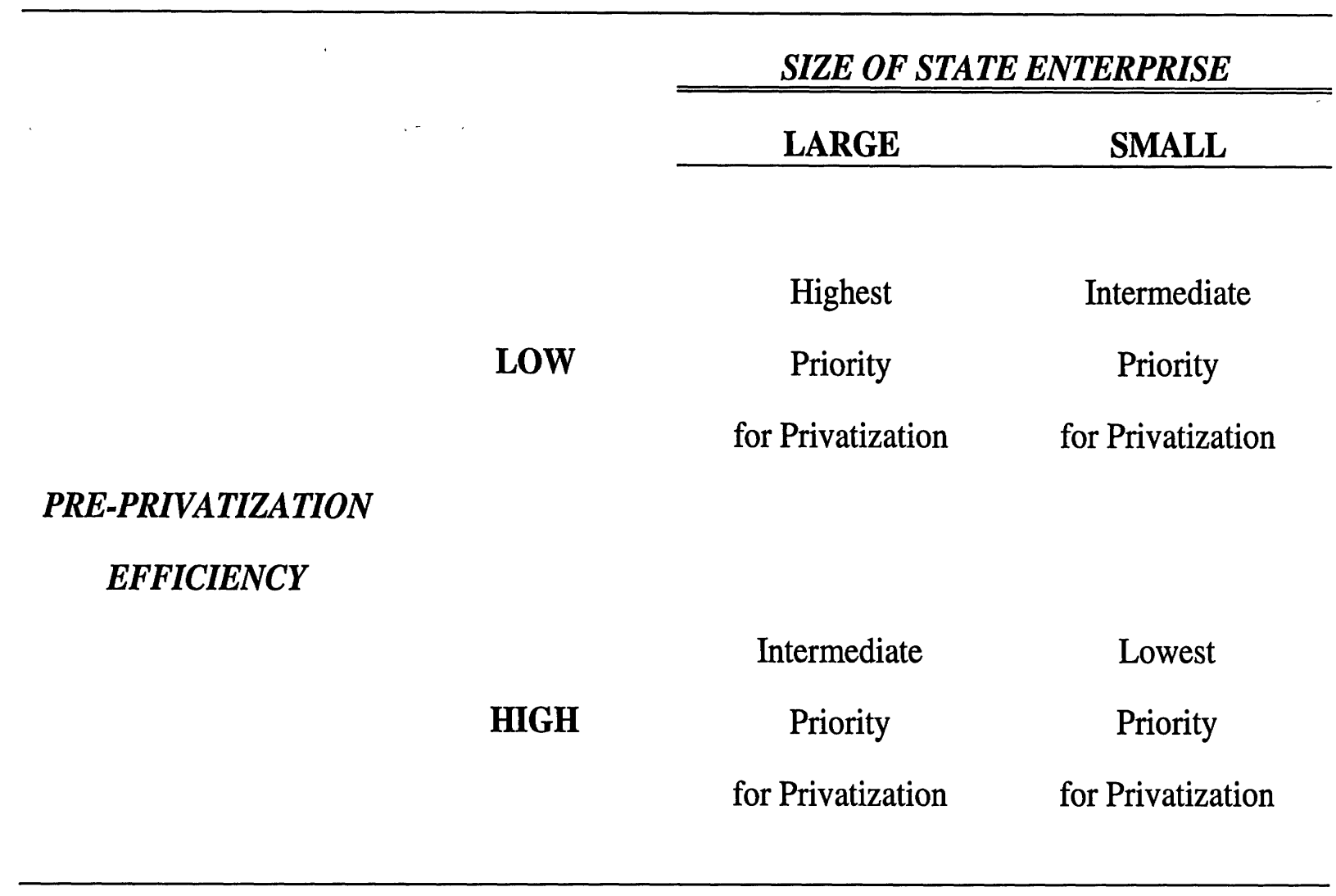




\section{TABLE 1: Descriptive Statistics for the Sample Firms 1}

$\begin{array}{cc}\text { Value-Added } & \\ \text { Mean } & 982.37 \\ \text { Standard Deviation } & 1518.87 \\ \text { Median } & 314.01 \\ \text { Maximum } & 6467.66 \\ \text { Minimum } & 27.48 \\ \text { Gross Fixed Assets } & \\ \text { Mean } & 7756.99 \\ \text { Standard Deviation } & 19361.43 \\ \text { Median } & 800.56 \\ \text { Maximum } & 102164.2 \\ \text { Minimum } & 20.64 \\ \text { Employment } & \\ \text { Mean } & 8758 \\ \text { Standard Deviation } & 11456 \\ \text { Median } & 3956 \\ \text { Maximum } & 48252 \\ \text { Minimum } & 659\end{array}$

1 All figures are five-year (1987 to 1991) averages; financial figures are presented in Rupees millions (Rs 31=\$1). 
TABLE 2: Efficiency Results for the Sample Firms 1

$\begin{array}{lr}\text { Number of firms } & 27 \\ \text { Mean Efficiency Score } & 0.445 \\ \text { Standard Deviation } & 0.262 \\ \text { Range } & 0.847 \\ \text { Inter-Quartile Deviation } & 0.416 \\ \text { Maximum } & 0.990 \\ \text { 75\%tile } & 0.635 \\ \text { 50\%tile } & 0.372 \\ \text { 25\%tile } & 0.219 \\ \text { Minimum } & 0.143 \\ \text { Coefficient of Variation } & 0.587\end{array}$

1 All figures are five-year (1987 to 1991) averages. 
TABLE 3: Illustrative Priority Schedule Based on Improvement Index Scores for a Sample of Indian State Enterprise

\begin{tabular}{|c|c|c|c|c|c|}
\hline $\begin{array}{c}\text { FIRM } \\
\text { NUMBER }\end{array}$ & $\begin{array}{c}\text { EFFICIENCY } \\
\text { SCORE }\end{array}$ & $\begin{array}{c}\text { EFFICIENCY } \\
\text { GAP }\end{array}$ & $\begin{array}{c}\text { TOTAL } \\
\text { ASSETS }\end{array}$ & $\begin{array}{c}\text { IMPROVEMENT } \\
\text { INDEX }\end{array}$ & $\begin{array}{l}\text { PRIVATIZATION } \\
\text { PRIORITY }\end{array}$ \\
\hline 1 & 0.22 & 0.78 & 12064.2 & 9410 & 1 \\
\hline 2 & 0.22 & 0.78 & 9609.3 & 7495 & 3 \\
\hline 3 & 0.16 & 0.84 & 9418.8 & 7912 & 2 \\
\hline 4 & 0.44 & 0.56 & 8955.1 & 5015 & 4 \\
\hline 5 & 0.30 & 0.70 & 2830.1 & 1981 & 5 \\
\hline 6 & 0.22 & 0.78 & 1836.4 & 1432 & 6 \\
\hline 7 & 0.46 & 0.54 & 1831.1 & 989 & 7 \\
\hline 8 & 0.92 & 0.08 & 1574.7 & 126 & 23 \\
\hline 9 & 0.31 & 0.69 & 1191.7 & 822 & 9 \\
\hline 10 & 0.38 & 0.62 & 1160.6 & 720 & 12 \\
\hline 11 & 0.38 & 0.62 & 1047.9 & 650 & 13 \\
\hline 12 & 0.16 & 0.84 & 1020.1 & 857 & 8 \\
\hline 13 & 0.18 & 0.82 & 889.7 & 729 & 11 \\
\hline 14 & 0.14 & 0.86 & 852.3 & 733 & 10 \\
\hline 15 & 0.77 & 0.23 & 804.0 & 185 & 20 \\
\hline 16 & 0.20 & 0.80 & 633.4 & 507 & 14 \\
\hline 17 & 0.86 & 0.14 & 598.6 & 84 & 24 \\
\hline 18 & 0.31 & 0.69 & 548.2 & 378 & 16 \\
\hline 19 & 0.27 & 0.73 & 547.6 & 400 & 15 \\
\hline 20 & 0.73 & 0.27 & 538.2 & 145 & 21 \\
\hline 21 & 0.32 & 0.68 & 505.2 & 344 & 18 \\
\hline 22 & 0.24 & 0.76 & 475.1 & 361 & 17 \\
\hline 23 & 0.47 & 0.53 & 372.0 & 197 & 19 \\
\hline 24 & 0.60 & 0.40 & 333.6 & 133 & 22 \\
\hline 25 & 0.99 & 0.01 & 170.1 & 2 & 27 \\
\hline 26 & 0.70 & 0.30 & 140.0 & 42 & 25 \\
\hline 27 & 0.63 & 0.37 & 98.1 & 36 & 26 \\
\hline
\end{tabular}


